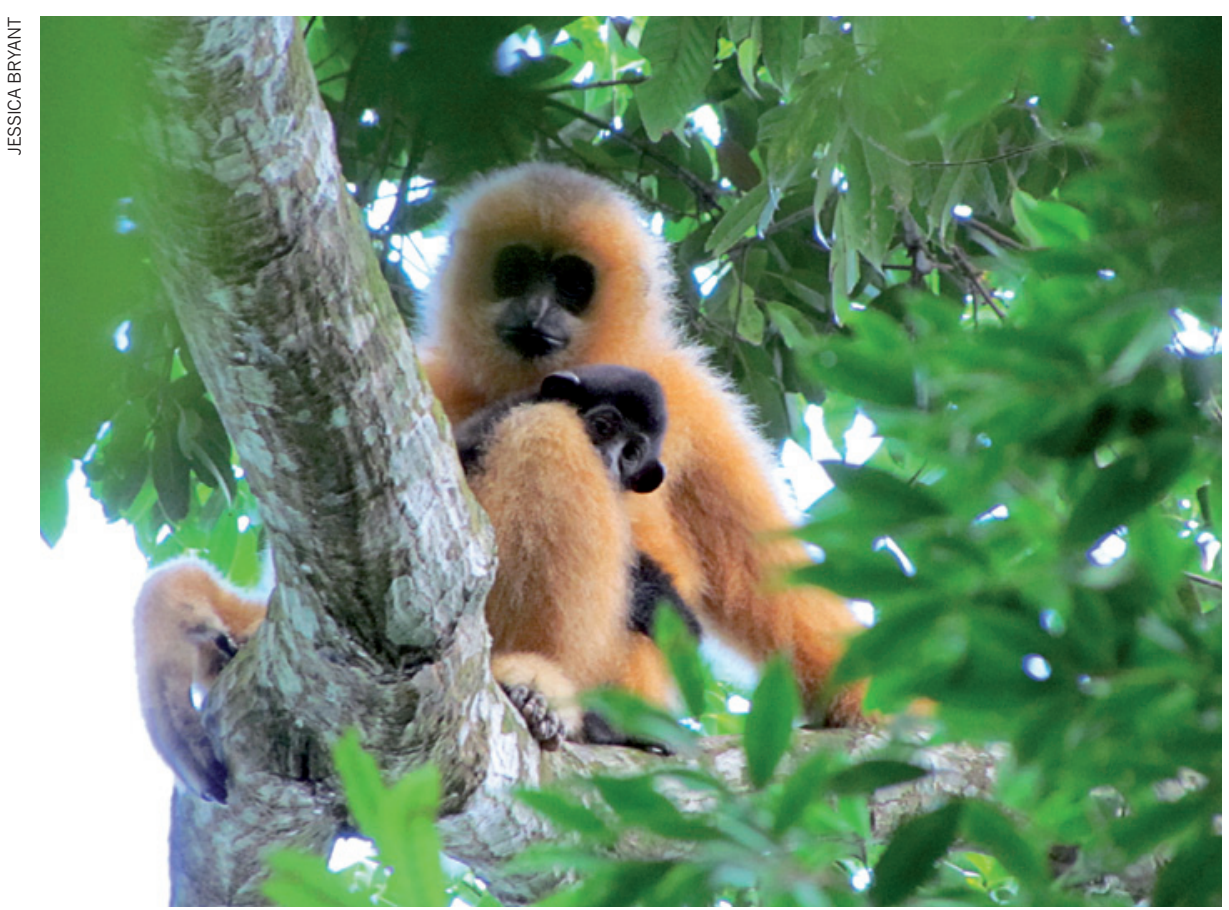

Fewer than $\mathbf{3 0}$ Hainan gibbons remain today.

CONSERVATION

\title{
Time running out for rarest primate
}

\section{Rescue bid launched to save Hainan gibbon from becoming first ape driven to extinction by humans.}

\section{BY DANIEL CRESSEY}

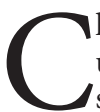
hina's wildlife conservation efforts are under scrutiny as scientists battle to save a species found only in a tiny corner of an island in the South China Sea. The Hainan gibbon is the world's rarest primate and its long-term survival is in jeopardy, according to an analysis.

Only 23 to 25 of the animals are thought to remain, clustered in less than 20 square kilometres of forest in China's Hainan Island. The species (Nomascus hainanus), which numbered more than 2,000 in the late 1950s, has been devastated through the destruction of habitat from logging, and by poaching. Extinction would give the gibbon the unwelcome distinction of being the first ape to be wiped out because of human actions. To hammer out a plan to save it, international primate researchers convened an emergency summit in Hainan last month.

"With the right conservation management, it is still possible to conserve and recover the Hainan gibbon population," says meeting co-chair Samuel Turvey, who studies animal extinctions at the Zoological Society of London (ZSL). "But given the current highly perilous state of the species, we cannot afford to wait any longer before initiating a more proactive and coordinated recovery programme." He adds that the meeting was a successful first step towards saving the animal and that a plan of action is being finalized.

The plan will be based in part on a 'population viability analysis' that models the potential size of the gibbon population in coming decades for a range of different scenarios. It is being drawn up by Kathy Traylor Holzer, a conservation planner at the Conservation Breeding Specialist Group in Apple Valley, Minnesota. "It's one of the smallest populations I've ever worked with," says Traylor Holzer. "That number - in one place - is extremely scary."

Preliminary modelling, which considers factors such as breeding success, habitat changes and natural threats, suggests that the Hainan gibbon may be safe from extinction in the next couple of decades. But its restricted habitat means that a single catastrophic event, such as a typhoon or a disease outbreak, could wipe out the minuscule population. Furthermore, low genetic diversity in the remaining animals could result in unhealthy offspring because of inbreeding. To better understand the genetics of the animals, ZSL researchers are conducting DNA sequencing using collected faeces.

Another potential problem is that the gibbons originally lived mainly in lowland forest, but logging has driven them to a higher altitude. Some scientists think that their current home might not be optimal for their needs, for example because it does not provide an adequate year-round supply of the fleshy fruits they prefer to eat.

Increased monitoring may be the key to the gibbons' conservation. Spotting the animals can be difficult, however, so researchers sometimes rely on the apes' social calls to find them. And Turvey notes that when young male gibbons leave the established social groups - a normal part of their life cycle after they reach sexual maturity - they tend to make fewer calls and are therefore difficult to find.

Bosco Chan, a specialist in Chinese conservation at the Kadoorie Farm and Botanic Garden in Hong Kong, says that one of the biggest challenges is finding enough suitable forest for the Hainan gibbon's population to expand into. Chan, who studies the gibbons and attended the meeting, notes that conservation in Hainan would also benefit other species: the gibbon is an 'umbrella species', meaning that measures taken to safeguard it will also protect the wider ecosystem of the island.

China has suffered major biodiversity losses through its rapid industrialization in recent decades. Although there are some notable conservation successes - such as for the giant panda - there have been major setbacks too; for example, the Yangtze river dolphin (Lipotes vexillifer) has been considered 'functionally extinct' since 2007 (see Nature http://doi. org/b2x2fh; 2006). Researchers hope that the Hainan gibbon will join the panda as an icon of conservation, reflecting China's renewed interest in protecting its wildlife.

"The government is paying more attention; the general public is paying more attention," says Chan. Turvey agrees, noting that representatives from a number of Chinese governmental institutions were at the workshop.

Chan is hopeful because he has seen more gibbons in recent years. "I'm quite positive. When I first started back in 2003, there were only 13 individuals we could confirm," he says. "Last year, we recorded 23."

\section{CORRECTION}

The affiliation for Joshua Tewksbury in the Editorial 'Natural decline' (Nature 508, 7-8; 2014) should have said he is director of the Luc Hoffmann Institute at the conservation group WWF in Gland, Switzerland. 